\title{
Toronto bridges to successful lung transplantation
}

\author{
Dirk Van Raemdonck, $\mathrm{MD}, \mathrm{PhD},{ }^{\mathrm{a}}$ Arne Neyrinck, $\mathrm{MD}, \mathrm{PhD},{ }^{\mathrm{b}}$ Robin Vos, $\mathrm{MD}, \mathrm{PhD},{ }^{\mathrm{c}}$ and \\ Geert M. Verleden, MD, $\mathrm{PhD}^{\mathrm{c}}$ \\ From the Departments of ${ }^{\mathrm{a}}$ Thoracic Surgery, ${ }^{\mathrm{b}}$ Anaesthesiology, and ${ }^{\mathrm{c}}$ Pneumology, University Hospitals Leuven, \\ Leuven, Belgium \\ Disclosures: Authors have nothing to disclose with regard to commercial support. \\ Received for publication Oct 30, 2017; accepted for publication Oct 30, 2017; available ahead of print Nov 29 \\ 2017. \\ Address for reprints: Dirk Van Raemdonck, MD, PhD, Department of Thoracic Surgery, University Hospital Gas- \\ thuisberg, Herestraat 49, B-3000 Leuven, Belgium (E-mail: dirk.vanraemdonck@uzleuven.be). \\ J Thorac Cardiovasc Surg 2018;155:1329-30 \\ $0022-5223 / \$ 36.00$ \\ Copyright (c) 2017 by The American Association for Thoracic Surgery \\ https://doi.org/10.1016/j.jtcvs.2017.10.103
}

According to Wikipedia, the Prince Edward viaduct over the Don River Valley is one of many crucial bridges in Toronto, Ontario, Canada. ${ }^{1}$ Also known as Bloor Viaduct, this double-decked arch bridge connects Bloor Street East on the west side with Danforth Avenue on the east with 5 vehicle lanes and 2 bicycle lanes on the upper level and 2 tracks of the Toronto subway on the lower level. While being vital for many commuters to enter the city, a barrier called the Luminous Veil was completed in 2003 to prevent the many suicide attempts from the viaduct.

Extracorporeal life support (ECLS) is increasingly being used for bridging to lung transplantation (LTx) in patients who deteriorate from respiratory insufficiency with hypoxia or hypercarbia or from right heart failure with pulmonary hypertension. Different ECLS modes are now available, each for specific indications. ${ }^{2}$ Recent improvement in technology and improved mobilization in the intensive care unit with extubation of patients while on ECLS have resulted in higher success rates and better outcome over recent years. 3

The article by Hoetzenecker and co-workers ${ }^{5}$ in this issue of the Journal reports on the institutional ECLS experience as a bridge to LTx at the University of Toronto. Between 2006 and 2016, 1111 LTxs were performed. In total, 71 candidates were bridged with the intention to LTx, including 11 patients $(16 \%)$ to retransplantation. Bridging practice gradually increased from $1.2 \%$ in 2006 to $12.6 \%$ in 2015. Eight patients died on ECLS, and 63 patients (89\%) reached transplant. The median duration on ECLS before LTx was 10 days (range, 0-95). Different ECLS modes were used according to the underlying indication. Of notice, 9 of 13 patients with pulmonary hypertension were bridged with a pumpless central membrane oxygenator (Novalung; Xenios, Heilbronn, Germany) inserted between the main pulmonary artery and the left atrium. More than one third of their patients could be extubated, and 26 patients were mobilized while on ECLS. Patient survival by intention to treat was $66 \%, 58 \%$, and $48 \%$ after 1,3 , and 5 years,

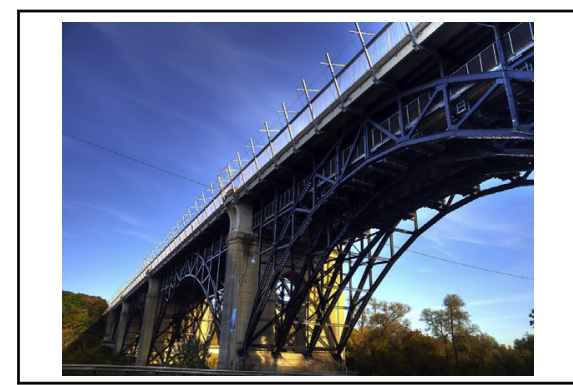

The Prince Edward Viaduct in Toronto, Ontario, Canada. Picture by Paul dexxus. CC BY 3.0. Available at: https://commons. wikimedia.org/w/index.php?curid= 11684569

\section{Central Message}

Candidates successfully bridged to first LTx have similar outcomes as those requiring no bridging. Survival after retransplantation in bridged patients is inferior to first transplants.

See Article page 1316.

respectively. Not surprisingly, patients on ECLS weaned from invasive ventilation had a higher chance $(49.2 \%)$ to survive until LTx compared with others $(12.5 \%$; $P=.053)$. More important, survival after LTx was not much different between recipients who were bridged versus patients undergoing transplantation without bridging $(76 \%$ vs $86 \%, 68 \%$ vs $72 \%$, and $55 \%$ vs $60 \%$ at 1,3 , and 5 years, respectively; $P=.197)$. However, patients successfully bridged to retransplantation had a lower median survival

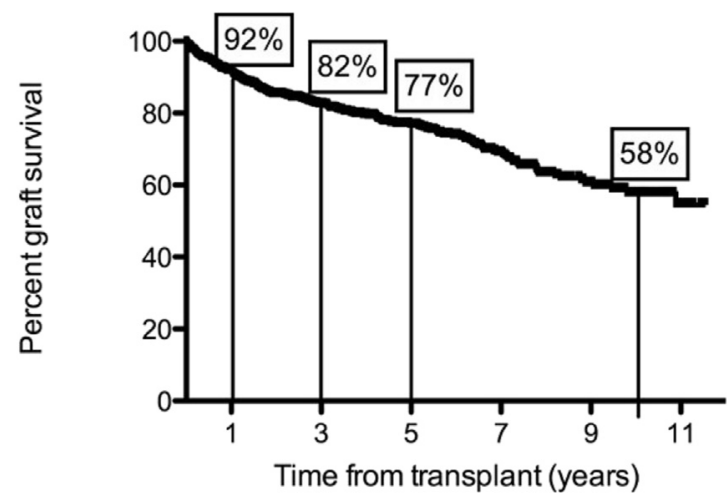

Subjects at risk $660586 \quad 418 \quad 293$

46

FIGURE 1. Overall survival in 660 patients who underwent transplantation at the University Hospitals Leuven, Belgium, between 2006 and 2016. 
(15 months) compared with those bridged for first transplantation (60 months; $P=.041$ ).

This is a unique report describing a large and difficult patient cohort over a short time period. The Toronto group should be applauded with their high survival $(89 \%)$ in patients bridged until transplantation. Other LTx centers can learn from their experience with different ECLS modes and bridging techniques varying over time for different indications. Although survival after LTx in the bridged cohort was only slightly less, overall survival in nonbridged patients appear somewhat inferior to results reported nowadays by other highvolume centers. In 660 patients undergoing transplantation at the University Hospitals Leuven, Belgium, between 2006 and 2016, overall survival is $92 \%, 82 \%$, and $77 \%$ at 1,3 , and 5 years (Figure 1) compared with $86 \%, 72 \%$, and $60 \%$, respectively, in Toronto over the same period. Moreover, waiting list mortality in our center is less than $2 \%$ versus $15.5 \%$ in the study by Hoetzenecker and colleagues. ${ }^{5}$ Although comparing results between centers is difficult because of potential differences in recipient profile and indications for LTx driving overall survival and waiting list mortality, the large gap in actual deceased donor rate per million population between Canada (19.0) and Belgium (31.6) may well explain the low percentage of patients that need bridging to LTx in our Leuven center. ${ }^{6}$
The Toronto group is to be acknowledged for their analysis of one of the largest institutional series on patients bridged to LTx so far. This article confirms that with modern ECLS methods including patient extubation and mobilization, LTx candidates have a high chance to survive the waiting period. Nevertheless, all efforts should focus on ways to increase national donor rates, thereby avoiding the need to construct more bridges in town for candidates to arrive in the transplant center on time.

The authors thank S. E. Verleden, PhD, for help with Figure 1.

\section{References}

1. List of bridges in Toronto. Available at: https://en.wikipedia.org/wiki/List_of_ bridges_in_Toronto. Accessed October 29, 2017.

2. Loor G, Simpson L, Parulekar A. Bridging to lung transplantation with extracorporeal circulatory support: when or when not? J Thorac Dis. 2017;9: 3352-61.

3. Diaz-Guzman E, Hoopes CW, Zwischenberger JB. The evolution of extracorporeal support as a bridge to lung transplantation. ASAIO J. 2013;59:3-10.

4. Hayanga AJ, Aboagye J, Esper S, Shigemura N, Bermudez CA, D'Cunha J, et al. Extra-corporeal membrane oxygenation as a bridge to lung transplantation in the United States: an evolving strategy in the management of rapidly advancing pulmonary disease. J Thorac Cardiovasc Surg. 2015;149:291-6.

5. Hoetzenecker K, Donahoe L, Yeung JC, Azad S, Fan E, Ferguson ND, et al. Extracorporeal life support as a bridge to lung transplantation - experience of a highvolume transplant center. J Thorac Cardiovasc Surg. 2018;155:1316-28.

6. Newsletter Transplant 2015. International Figures on Donation and Transplantation; volume 21. European Directorate for the Quality of Medicines \& Health Care, Council of Europe; 2016. Available at: http://www.ont.es/publicaciones/ Documents/NEWSLETTER 2016 NIPO.pdf. Accessed October 29, 2017. 